\title{
Particle Erosion Behavior of Unidirectional CF and GF Hybrid Fiber - Reinforced Plastic Composites
}

\author{
QIAN Danna ${ }^{\mathrm{a}}$, BAO Limin ${ }^{\mathrm{b},{ }^{*}}$, TAKATERA Masayuki ${ }^{\mathrm{b}}$, KEMMOCHI Kiyoshi ${ }^{\mathrm{b}}$ \\ ${ }^{a}$ Graduate School of Shinshu University, 3-15-1, Tokida, Ueda-shi, Nagano 386-8567, Japan \\ ${ }^{\mathrm{b}}$ Faculty of Textile Science and Technolgy, Shinshu University, 3-15-1, Tokida, Ueda-shi, Nagano 386-8567, Japan
}

Received 28 June 2007; accepted for publication 14 January 2009

\begin{abstract}
Unidirectional carbon fiber- or glass fiber- reinforced composites as structure materials have wide applications in many industries. In order to combine the advantages of these two fibers, both carbon fiber and glass fiber are employed as reinforcing elements in single unsaturated polyester resin, and hybrid composites are formed. In this study, the erosion behavior of CF/GFRP and GF/CFRP were investigated at different impact angles $\left(15-90^{\circ}\right)$ and compared with CFRP and GFRP on fiber orientation $90^{\circ}$. The results suggested that CF/GFRP was low erosion wear as compared to GF/CFRP. Scanning electron microscopy was used to characterize the morphology of eroded surfaces. The micrographs revealed that $\mathrm{CF}$ and GF were maintained their own erosion behavior in the hybrid composite materials as well in the neat FRP materials. The simple analytical approach was constructed to figure out the theoretic erosion behavior, which were compared to the experimental results. It was confirmed that the erosion behavior of the hybrid composite materials could be predicted by the proposed analytical approach.
\end{abstract}

Key Words: Erosion wear, Unidirectional fiber- reinforced hybrid composites, Carbon fiber, Glass fiber

\section{Introduction}

Solid particle erosion [1-3] is one type of wear that causes local damage combined with the progressive loss of original material from a solid surface due to mechanical interaction between that surface and solid particles. Fiber-reinforced polymer (FRP) composites materials have been widely used in various engineering fields because of their superior specific strength, lower density, and high corrosion resistance compared to monolithic metal alloys. It has been reported that various applications of FRP in equipment expose it to erosion wear conditions. Some examples include helicopter rotor blades, pump impeller blades, highspeed vehicles, and aircraft operating in desert environments.

Since the 1980s [4-6], the investigation of the erosion behavior of materials has been extended from metals to polymers and their composites. Mostly experiments involving polymer composites have been summarized and listed by A.P. Harsha and co-workers [7-9]. Across the literatures, it is widely recognized that polymers and their composites have poorer erosion resistance than metals, except for rubbers, and that polymer composites containing reinforcement fiber usually erode faster than neat polymers [7, 10-12]. For unidirectional fiber-reinforced composites, the basic element of complex composite structural material, the degree of the erosion wear appears to vary with fiber orientation. However, the erosion resistance of carbon-fiber reinforced polymer (CFRP) has proven to be higher than glass-fiber reinforced polymer (GFRP).

In practice, glass fiber (GF) is widely used as a composite reinforcement material due to its high strength-to-weight ratio, and its cost, which is lower than that of carbon fiber (CF). However, CF's primary advantages over GF are its higher modulus, high strength, lower density, improved creep-rupture resistance, and lower coefficient of thermal expansion. In order to combine the advantages of these two fibers, CF has been added to GF-reinforced composites. Composites containing a combination of different fibers are called hybrid composites. Many papers have been published concerning the erosion of FRP materials and the mechanical properties of carbon- fiber based hybrid composites [13, 14], in which there were few erosion behaviors described for CF/GF interply hybrid composites.

To find the erosion mechanism of hybrid materials and develop new materials with excellent functionality and

* Corresponding author: E-mail: baolimin@shinshu-u.ac.jp, Tel: +81-268-21-5423 
erosion resistance, this study investigated the erosion behavior of unidirectional CF/GF-FRPs hybrid materials as compared to GFRP and CFRP. And the damaged surfaces of them were observed by SEM. Furthermore, the numerical analytical approach using for predicting erosion behaviors of hybrid material was theorized.

\section{Experimental}

\section{1 Materials}

In this work, the FRP was constructed as a unidirectional carbon-fiber and glass-fiber for reinforcement, with unsaturated polyester resin as matrix, all of which were assembled by hand lay-up in the laboratory. The CF and GF were supplied by Mitsubishi Rayon Co. Ltd. and Unitika Co. Ltd., respectively. The arrangement of the laminae as $(\mathrm{GF}-\mathrm{CF}) \times 3$ in hybrid material was shown in Fig. 1. In order to keep the same volume fraction of fiber $\left(V_{f}\right)$ in hybrid materials, all the specimens were cut from one board. GF/CFRP represents an erosion surface from GF to $\mathrm{CF}$, following pattern the same as CF/GFRP. The $V_{f}$ of the GFRP and CFRP were approximately $45 \%$. The square samples sized $25 \mathrm{~mm} \times 25 \mathrm{~mm} \times 3 \mathrm{~mm}$ were cut for erosion testing.

\section{2 Erosion wear testing}

A schematic diagram of the erosion tester used is presented in Fig. 2. The particles were fed into an air stream at room temperature by a vibrating hopper. The feed rate was determined by the frequency of vibration and the inclination of the hopper. The velocity of the impact particles was controlled by adjusting the inlet pressure of a gun nozzle (NAB-11-6, Trucso Nakayama Co.). The testing conditions are listed in Table 1. The erosion wear of these composites was evaluated at different impact angles (from $15^{\circ}$ to $90^{\circ}$ ) at fiber orientations of $90^{\circ}$. The mounted specimens were subjected to a particle flow at a given impingement angle and a given angle of fiber orientation, as illustrated in Fig. 3.

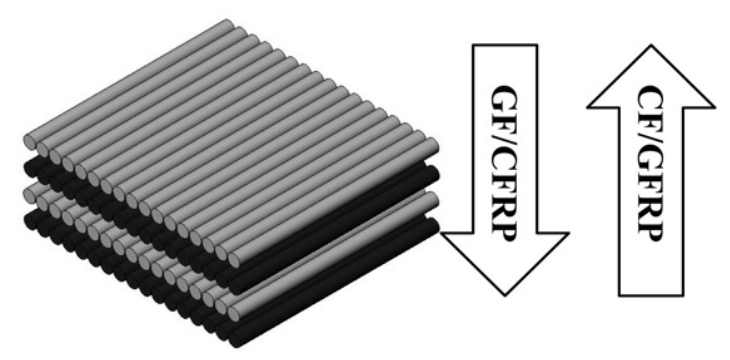

Fig. 1 Model of the erosion hybrid specimens.

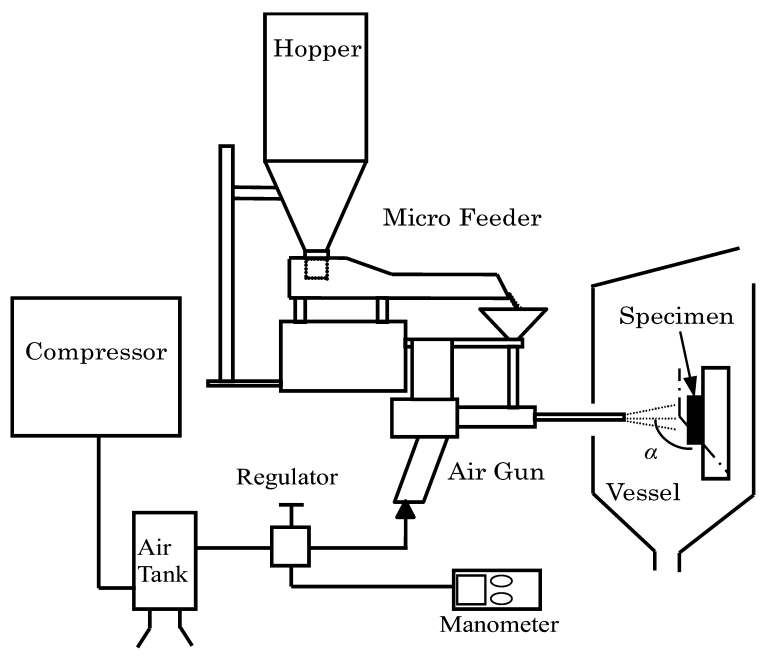

Fig. 2 Schematic diagram of the erosion tester.

Table 1 Erosion test conditions.

\begin{tabular}{lc}
\hline Test parameters & \\
\hline Erodent & Alumina solid \\
Erodent size $(\mu \mathrm{m})$ & $11.50 \pm 21.50$ \\
Erodent shape & Angular \\
Impact angle $\left(\alpha^{\circ}\right)$ & $15,30,45,60,75,90$ \\
Fiber orientation & $90^{\circ}$ \\
Impact velocity $(\mathrm{m} / \mathrm{s})$ & 127.4 \\
Average erodent feed rate $(\mathrm{g} / \mathrm{min})$ & 1.4 \\
Test temperature & $\mathrm{RT}$ \\
Nozzle-to-sample distance $(\mathrm{mm})$ & 40 \\
Nozzle inner diameter $(\mathrm{mm})$ & 5.3 \\
\hline
\end{tabular}

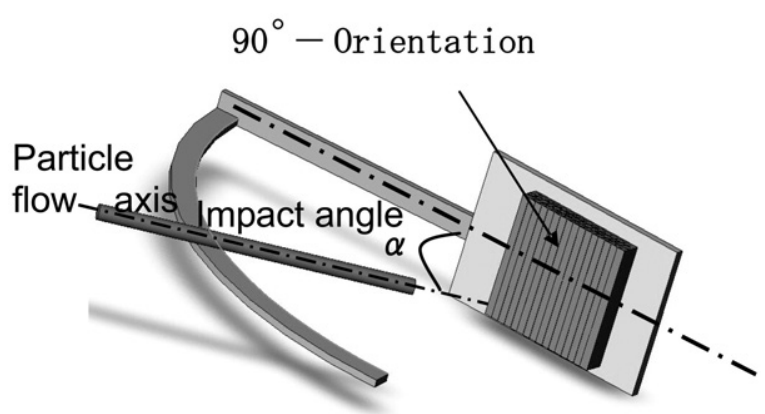

Fig. 3 Definition of impact angle and fiber orientation.

\section{Results and discussion}

Among a great deal of factors influencing the erosion wear of materials, the most important are the impact velocity; impact angle of the erodent particles; and the size, shape and hardness of the particles. In this paper, the exposure time and the impact angle are examined under the velocity of $127 \mathrm{~m} / \mathrm{s}$ with specific eroding particles. 


\section{1 Effect of exposure time}

After impact of every 5, 10, 15, 20, 30, and 40 minutes at the impact angle of $90^{\circ}$, the weight of the specimen was measured by a balance, respectively.

Exposure time is defined as a measure of the accumulation of exposure to erosion or to a wear environment. Figure 4 plots weight loss as a function of exposure time for four structures. At the ideal conditions, while both the first $\mathrm{CF}$ layer and the first GF layer counted from the erosion surface were drilled through by particle impacting, the GF/CFRP and the CF/GFRP will reach the same weight loss at a certain time (defined as appropriate time), and the erosion damage should change in accordance with the two alternately uptilting lines. However, as compared with the experimental results, this pattern was not apparent in Fig. 4. The discrepancy could be attributed to the exposure time stages, none of which was close to the appropriate time

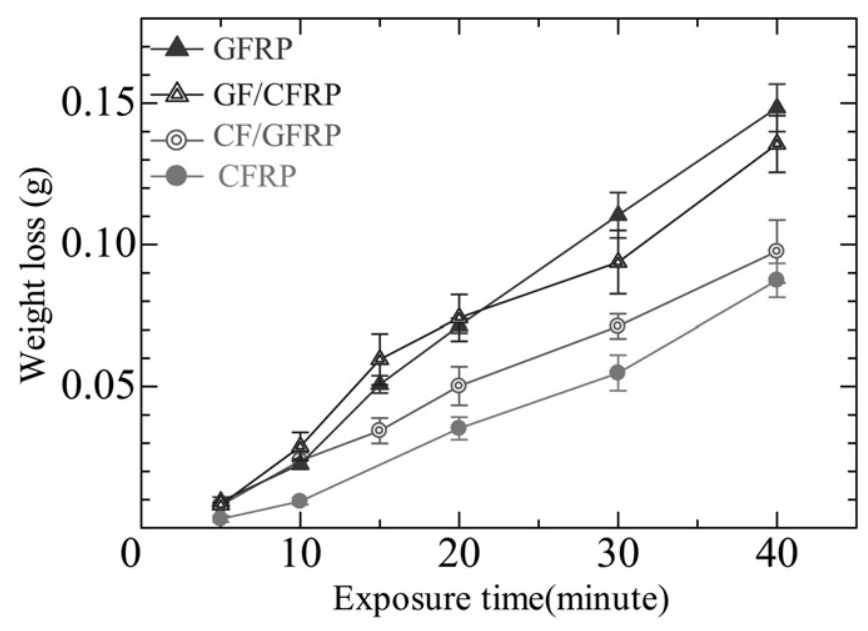

Fig. 4 Weight loss as a function of exposure time.

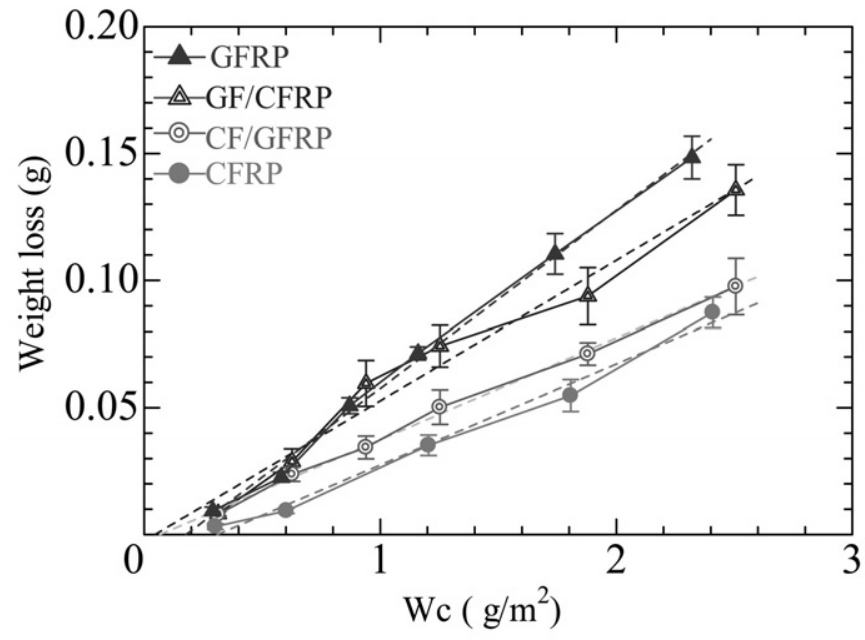

Fig. 5 Weight loss as a function of the weight of an impact particle on unit area. because it was very difficult to determine.

After being for 5 minutes, the weight losses of the three types were almost the same, which could be interpreted as resulting from wear damage of the matrix resin. From then on, differences between $\mathrm{GF} / \mathrm{CF}$ and $\mathrm{CF} / \mathrm{GF}$ were observed in evidence, with the weight loss of the former being higher than that of the latter. Interestingly, from 15 to 30 minutes, two parallel gradient lines were observed resulting from the low density, higher erosion resistance of $\mathrm{CF}$ and the lamina arrangement. In the case of GF/CFRP, the CF lamina became the major erosion object after the first GF lamina ruptured. Therefore, the decrease in the GF fraction and the increase in the resistant $\mathrm{CF}$ fraction resulted in a reduced weight loss as compared to the former time stage. The reverse was true, in the case of CF/GFRP resulting in an increasing weight loss.

For GFRP and CFRP, the weight loss was regarded as a linear-growth equation with increasing exposure time. Since the measured feed rate, $1.3 \mathrm{~g} / \mathrm{min}$ in the GFRP testing, was slightly lower than in hybrid material with fluctuating vibrations, the weight loss before 20 minutes is lower in GFRP than in GF/CFRP.

In order to clarify these relationships, the exposure time used as the x-coordinate in Fig. 4 can be converted to the weight of an impact particle impacting the unit damaged area $\left(W_{c}\right)$ shown in Fig. 5, according to the following equation:

$$
\begin{aligned}
& \rho_{\text {impact }} \frac{\rho(\mathrm{g} / \mathrm{min})}{v \times A\left(\mathrm{~m}^{3} / \mathrm{min}\right)} \times v(\mathrm{~m} / \mathrm{min})=\frac{\rho}{A}\left(\mathrm{~g} / \mathrm{m}^{2} \cdot \mathrm{min}\right) \\
& W_{\mathrm{c}}=\rho_{\text {impact }} \times t\left(\mathrm{~g} / \mathrm{m}^{2}\right)
\end{aligned}
$$

Where $\rho_{\text {impact }}$ is the density of the impact particle; $\rho$ is the weight of the particles in unit time; and $v, A, t$ are the velocity of the stream, the impact area, and the exposure time, respectively.

Linear least-squares method revealed that the data for GF/CFRP was distributed around a line that did not pass through the origin as shown in Fig. 5. It is evident that the weight loss of GF/CFRP was no better than the GFRP during the initial period of composite eroding. With increasing exposure time, the difference between the materials containing $\mathrm{CF}$ and those not containing $\mathrm{CF}$ was easy to see. There was little change in the tendency of the CF/GFRP and CFRP as compared with Fig. 4. The average erosion resistance of the GF/CFRP is lower than the $\mathrm{CF} / \mathrm{GFRP}$ under the whole testing period at the impact angle of $90^{\circ}$. It was revealed that the arrangement of the carbon lamina and the glass lamina has significantly influences on the erosive wear of composites. 


\section{2 Effect of impact angles}

After impact of 20 minutes from 15 to $90^{\circ}$, almost all the interface between the first and second laminae of the specimens were penetrated through, and only the first interface between the CF and GF lamina was drilled through.

Figure 6 illustrated the influence of the impact angles on weight loss of four kinds of specimens. The broken curves were gained from all of the examination values analyzed by two-stage least squares method. It can be seen that the weight loss values of hybrid materials were keeping in the middle of the GFRP and CFRP. And all of the maximum weight loss values were approaching to the impact angle of $60^{\circ}$ in the broken curves. This was semi ductile erosion behavior [10]. The shapes of the curves were similar in both cases. This erosion result was mostly in agreement with those summarized by other groups $[10,15,16]$.

\section{3 Observation of damaged surface}

Figure 7(a) and (b) are SEM micrographs of surface features in GFRP tested with the fiber oriented at $90^{\circ}$ and an impact angle of $90^{\circ}$. The initial stages of resin removal and the later stages of fiber breakage and subsequent fiber removal are depicted. The removal of the resin results in the exposure of the fiber. Because GF is a typically brittle material, the continuous impact of particles caused the cracks on the fiber surface in all directions. With the extending of the cracks, fiber fragments were generated, causing fiber breakage, as shown in Fig. 7(b). The damage on GF was developed from the upside surface to underside with the particles impacting.

Although CF is a brittle material as well, it can be observed in Fig. 8 that cracks on the fiber surface were

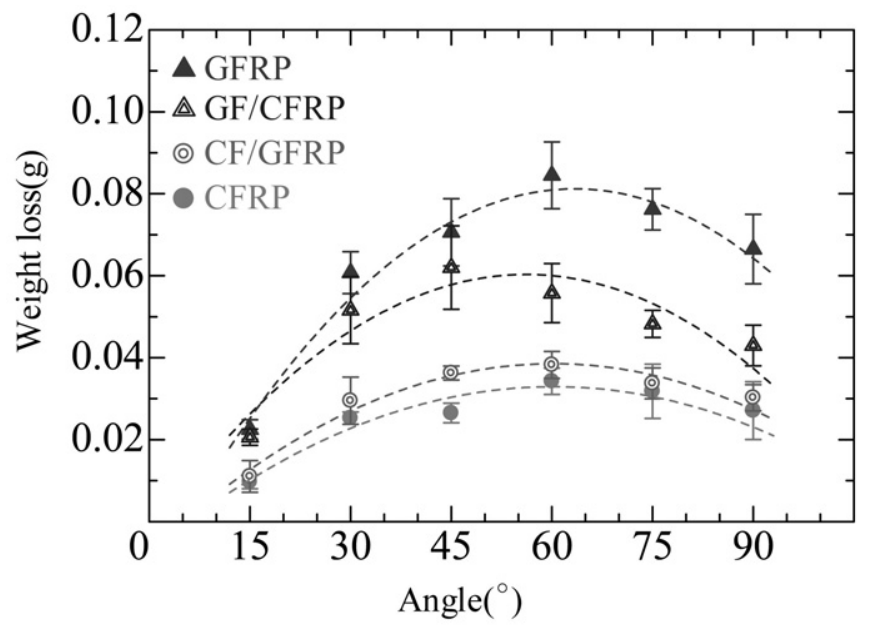

Fig. 6 Weight loss as a function of the impact angles. extended along directions almost parallel to the fiber axis and perpendicular to it, which differed from GF. In addition, the degree of damaged in the former case was less than in the latter.

In the case of CF/GFRP and GF/CFRP, $\mathrm{CF}$ and $\mathrm{GF}$ were maintained their own behavior in the hybrid composite materials in Fig. 9. It is easy to compare and contrast the interface for CF/GFRP with in that for GF/CFRP using two micrographs. Especially, in Fig. 9 (a), it can be seen

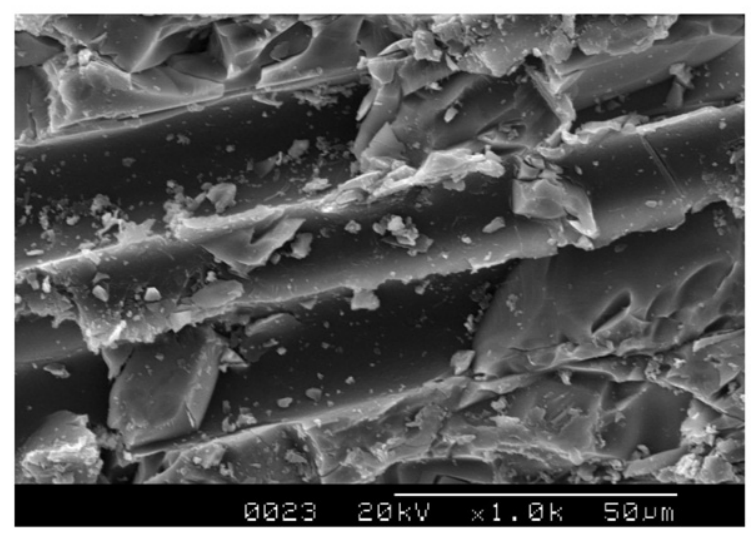

(a)

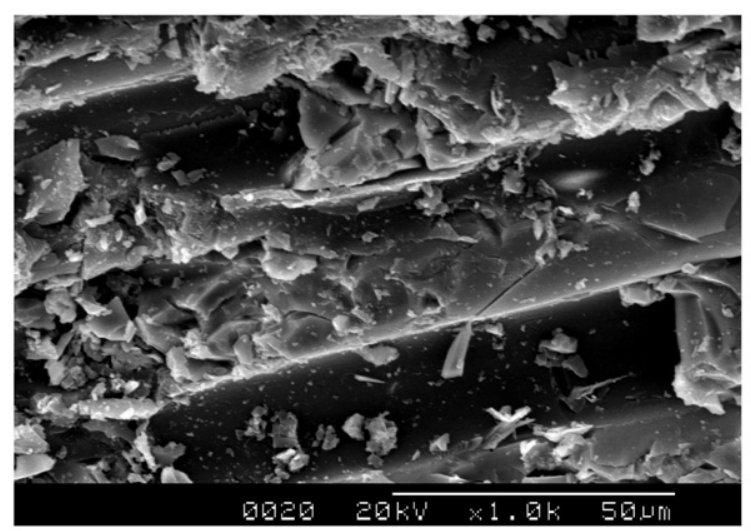

(b)

Fig. 7 SEM micrographs of surface features in GFRP.

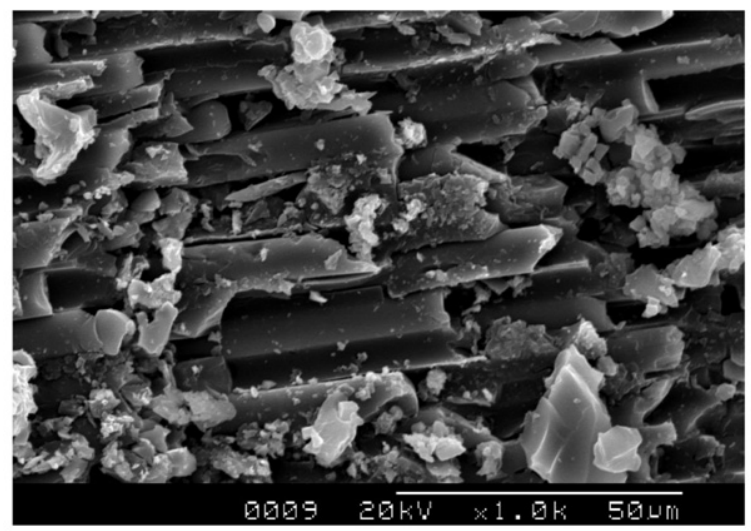

Fig. 8 SEM micrographs of surface features in CFRP. 


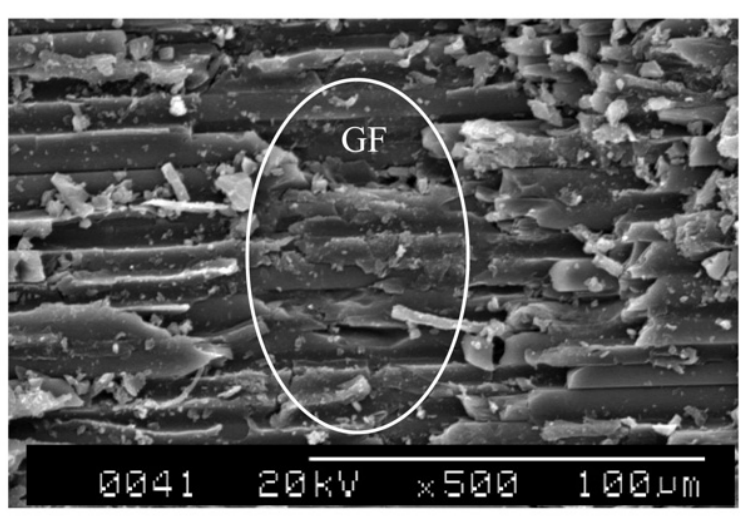

(a)

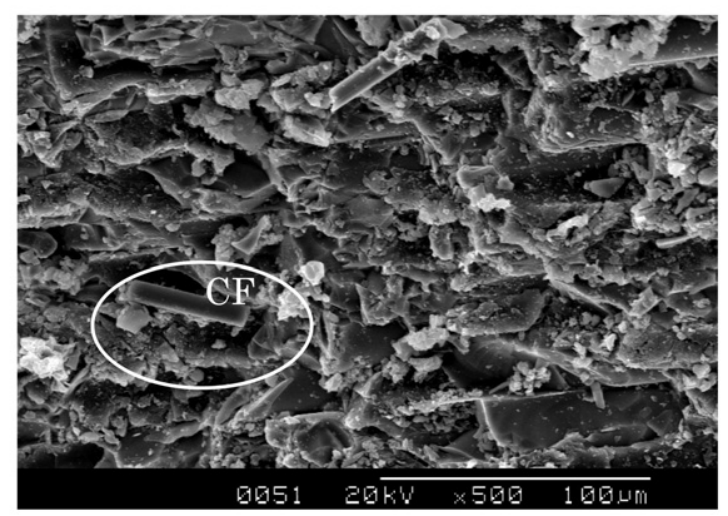

(b)

Fig. 9 SEM micrographs of hybrid material, exposure time =20min; $\mathrm{v}=127 \mathrm{~m} / \mathrm{s}$; (a) CF/GFRP, (b) GF/CFRP.

evidently that the GF had begun to disintegrate before the resin was completely removed.

\section{4 Theoretic analytical approach}

Based on SEM micrographs, it was considered that the erosion mechanisms of CF and GF were not changed in hybrid material and the erosion was owed to the damage of simple assembly of the CF and GF laminations. Therefore, it was necessary for us to calculate the weight losses of hybrid material from the experiment data of neat CFRP and GFRP as much as possible.

By observing the erode specimens in the experiments, the shape of the cross-section of erosion surface was camber. However, the theoretic model was presumed as a column based on the tentative of the wear damage changing along the regular round in shape. The error of the model was ignored. The diameters of the damage surface were expressed by $\psi_{C}$ and $\psi_{G}$ for CFRP and GFRP, respectively. The interrelated parameters such as the fiber content, the density of materials, and the thickness of the fiber layer, were shown in Table 2. The damage volumes $(V)$ of hybrid materials could be approximately measured following the erode specimens. The $\rho$ was the density of the neat FRP materials.
Table 2 Parameters of neat CFRP and GFRP materials.

\begin{tabular}{cccc}
\hline & & CFRP & GFRP \\
\hline $\begin{array}{c}\text { Fiber content } \\
\text { Vol.\% }\end{array}$ & & 43 & 45 \\
$\begin{array}{c}\text { Density } \\
\left(\mathrm{g} / \mathrm{cm}^{3}\right)\end{array}$ & $\rho$ & 1.335 & 1.705 \\
Thickness & $t_{C}$ & 0.0288 & - \\
$(\mathrm{cm})$ & $t_{G}$ & - & 0.0195 \\
Damaged diameter & $\psi_{C}$ & 0.95 & - \\
$(\mathrm{cm})$ & $\psi_{G}$ & - & 1.15 \\
\hline
\end{tabular}

Erosion rate of composites $(R)$ were defined by following equations, and the suffixes ' $C$ ' and ' $G$ ' meant the CFRP and GFRP, respectively,

$$
R_{c}=\frac{W_{L C}}{W_{S}}, R_{G}=\frac{W_{L G}}{W_{S}}
$$

where $W_{L C}$ and $W_{L G}$ were the weight loss values obtained from testing, and the $W_{S}$ was the total weight of the impactive erodent, which was a constant. It can be divided into two parts, one of which was used for the erosion of the CF lamina $\left(W_{S C}\right)$, and the other was for the GF lamina $\left(W_{S G}\right)$. It could be expressed by Eq.(4).

$$
W_{S}=W_{S G}+W_{S C}
$$

In theory, homoplastically, there were two corresponding parts, the weight loss of GF lamina $\left(W_{L G}^{\prime}\right)$ and the weight loss of CF lamina $\left(W_{L C}^{\prime}\right)$, in the weight loss of the hybrid material $\left(W_{L}^{\prime}\right)$, which could be expressed as follows:

$$
W_{L}^{\prime}=W_{L G}^{\prime}+W_{L C}^{\prime}
$$

In case of the calculating of the GF/CFRP, the first of all, the theoretic weight loss of the first GF lamina $\left(W_{L G}^{\prime}\right)$ can be obtained by Eq.(6), which was available to the situation of all six impact angles.

$$
W_{L G}^{\prime}=V \times \rho_{G F R P}
$$

Then taking the impact angle at the $60^{\circ}$ for example, the $R_{G}$ and $R_{C}$ at the $60^{\circ}$ could be gained using the $W_{L G}$ and $W_{L C}$ at the $60^{\circ}$ by Eq.(3). Therefore, the $W_{S G}$ was easy to get by Eq.(7).

$$
W_{S G}=\frac{W_{L G}^{\prime}}{R_{G}}=\frac{V \times \rho_{G F R P}}{R_{G}}
$$

Applying the $W_{S C}$ and $R_{C}$ into Eq.(8), the weight loss of the CF lamina could be obtained.

$W_{L C}^{\prime}=W_{S C} \times R_{C}$

It should be pay more attention to one point. During the Eq.(7), if the gained $W_{S G}$ was larger than $W_{S}$, it meant that the quantity of the erodent was not much enough to wear through the first GF lamina to arrive at the CF lamina. In 


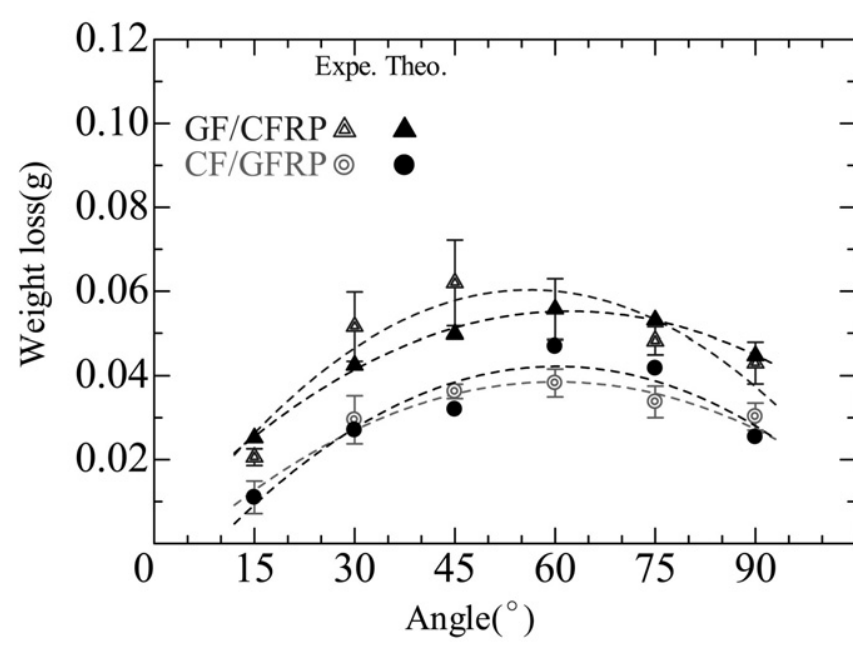

Fig. 10 Comparison of the experimental data with the theoretic data.

this instance, Eq.(6) and Eq.(7) were not used, and Eq.(5) was changed to Eq.(9).

$$
W_{L}^{\prime}=W_{L G}^{\prime}=W_{S} \times R_{G}
$$

As the erosion rate was different with each other under the each impact angle, it was necessary to figure out all of the $R_{G}$ and $R_{C}$ with the changing of the $W_{L G}$ and $W_{L C}$. According to the above flow, it could obtain the $W_{L G}^{\prime}$ from 15 to $90^{\circ}$, as shown in Fig. 10 with the black triangles.

In case of the calculating of the CF/GFRP, it could used the similar equations following the same flow of GF/CFRP to obtain the $W_{L}^{\prime}$ from 15 to $90^{\circ}$, as shown in Fig. 10 with the black rotundities.

Then the theoretic data of weight loss of hybrid materials were analyzed by two-stage least squares method as shown in Fig. 10. To compare with the experimental broken curves, it can be seen that not only the shape but also the peak of the broken curves were at close range in the case of CF/GFRP, which was also in the same with GF/CFRP. The absolute errors of the two groups were $13.8 \%$, and $14.2 \%$ in $\mathrm{CF} / \mathrm{GFRP}$ and GF/CFRP, respectively, which were considered as the summation of the model error and experimental error. The result was validated that the erosion behavior of reinforced fibers in hybrid materials were in the same with which in the neat FRP materials. Thus, it came to the conclusion that the erosion behavior of the hybrid composite materials could be predicted by several simple equations based on lamination rules of composite materials.

Thus, to meet the demand in various fields and reduce the cost, the hybrid FRP materials in possession of high erosion resistance can be assembled with various reinforced fiber laminas.

\section{Conclusions}

On the basis of the comparison of solid particle erosion of unidirectional hybrid composites with CF/GFRP and
GF/CFRP, the following conclusions were drawn:

1. The erosion of CF and GF hybrid FRP was higher than that of CFRP but lower than that of GFRP. The arrangement of the carbon lamina and the glass lamina has significantly influences the erosive wear of composites. The erosion breakage in CF/GFRP was high compared to GF/CFRP at all impact angles.

2. The morphology of eroded surfaces observed by SEM revealed that the erosion of brittle materials erosion begins with fiber cracking and extends to fiber fractions, resulting in broken fibers. And CF and GF were maintained their own behavior in the hybrid composite materials as well in the neat FRP materials.

3. By the simple analytical approach, the theoretic results corresponded with the experimental result. It was revealed that the erosion behavior of the hybrid composite materials could be predicted by the theoretic analytical approach.

\section{Acknowledgements}

This work was supported by Grant-in-Aid for Global COE Program by the Ministry of Education, Culture, Sports, Science, and Technology.

\section{References}

[1] Friedrich K (1986) J Mater Sci, 21, 3317-3332

[2] Ruff AW, Ives LK (1975) Wear, 35, 195-199

[3] Arai K, Tsuda K, Hojo H (1987) J Mater Sci Soc Japan, 24, 90-96

[4] Pool KV, Dharan CKH, Finnie I (1986) Wear, 107, 1-12

[5] Sundararajam G, Roy M, Venkataraman B (1990) Wear, 140, 369-281

[6] Roy M, Vishwanathan B, Sundararajan G (1994) Wear, 171, 149-161

[7] Harsha AP, Tewari US, Venkatraman B (2003) Wear, 254, 693-712

[8] Tewari US, Harsha AP, Häger AM, Friedrich K (2003) Compos Sci Technol, 63, 549-577

[9] Tewari US, Harsha AP, Häger AM, Friedrich K (2002) Wear, 252, 992-1000

[10] Häger A, Friedrich K, Dzenis YA, Paipetis SA (1995) "Study of erosion wear of advanced polymer composites", pp155-162, in: K. Street, B.C. Whistler (Eds.), Proceedings of the ICCM10, Canada Woodhead Publishing Ltd., Cambridge

[11] Barkoula NM, Karger-Kocsis J (2002) Wear, 252, 80-87

[12] Miyazaki N, Takeda N (1994) J Compos Mater, 28, 871-883

[13] Jang J, Lee C (1998) Polym Test, 17, 383-394

[14] Dutra RCL, Soares BG, Campos EA, Silva JLG (2000) Polym, 41, 3841-3849

[15] Zahavi J, Schmitt Jr GF (1981) Wear, 71,179-190

[16] Miyazaki N, Takeda N (1993) J Compos Mater, 27, 21-31 